\title{
The Role of Notch Signaling Pathway in Non-Alcoholic Fatty Liver Disease
}

\author{
Hao Xu and Lin Wang * \\ Department of Hepatobiliary Surgery, Xi-Jing Hospital, The Fourth Military Medical University, Xi'an, China
}

Non-alcoholic fatty liver disease (NAFLD) is the most common chronic liver disease worldwide, and progressive NAFLD can develop into non-alcoholic steatohepatitis (NASH), liver cirrhosis, or hepatocellular carcinoma (HCC). NAFLD is a kind of metabolic disordered disease, which is commonly associated with lipid metabolism, insulin resistance, oxidative stress, inflammation, and fibrogenesis, as well as autophagy. Growing studies have shown Notch signaling pathway plays a pivotal role in the regulation of NAFLD progression. Here, we review the profile of the Notch signaling pathway, new evidence of Notch signaling involvement in NAFLD, and describe the potential of Notch as a biomarker and therapeutic target for NAFLD treatment.

\section{OPEN ACCESS}

Edited by:

Jinhang Gao,

Sichuan University, China

Reviewed by:

Huichang Bi,

Sun Yat-sen University, China

Xiang Zhang,

The Chinese University of Hong Kong,

China

Lei Chen,

Eastern Hepatobiliary Surgery Hospital, China

*Correspondence:

Lin Wang

fierywang@163.com

Specialty section:

This article was submitted to

Molecular Diagnostics and

Therapeutics,

a section of the journal

Frontiers in Molecular Biosciences

Received: 11 October 2021

Accepted: 01 November 2021

Published: 24 November 2021

Citation:

$\mathrm{Xu} H$ and Wang L (2021) The Role of Notch Signaling Pathway in Non-

Alcoholic Fatty Liver Disease. Front. Mol. Biosci. 8:792667. doi: 10.3389/fmolb.2021.792667
Keywords: Notch signaling pathway, non-alcoholic fatty liver disease (NAFLD), steatohepatitis, lipid metabolism, insulin resistance (IR), fibrogenesis, autophagy

\section{INTRODUCTION}

Non-alcoholic fatty liver disease (NAFLD), affecting over a quarter of the global population, has emerged as the highest prevalent type of chronic liver disease (Younossi et al., 2016). NAFLD encompasses a spectrum of progressive liver diseases including simple steatosis (SS), non-alcoholic fatty steatohepatitis (NASH), fibrosis, cirrhosis, and hepatocellular carcinoma (HCC) (D. Q. Huang et al., 2021; Powell et al., 2021). NAFLD is defined by the presence of steatosis in $>5 \%$ of hepatocytes in histological analysis and exclusion of excessive alcohol consumption daily ( $\geq 30 \mathrm{~g}$ for men and $\geq 20 \mathrm{~g}$ for women) (EASL et al., 2016). Evidence suggests that NAFLD is related to liver manifestations of metabolic syndrome such as obesity, diabetes, insulin resistance (IR), and dyslipidemia (Younossi et al., 2018; Jarvis et al., 2020).

The individual clinical outcomes of patients with NAFLD are highly variable. For the majority of patients with simple steatosis, their liver disease is in non- or slow-progression. A prospective cohort study reported in a three-year period, over $20 \%$ of patients with simple steatosis developed into NASH (Wong et al., 2010), a more severe stage in which fatty liver is accompanied by necroinflammatory changes like hepatocyte ballooning and lobular inflammation (Vernon et al., 2011). In the final stages, collagen deposition and subsequent vascular remodeling result in fibrosis and cirrhosis (EASL et al., 2016). Thus far, there is no accurate non-invasive diagnostic biomarker and effective treatment toward NAFLD (Francque and Vonghia, 2019; Younossi, 2019), and current therapy is mainly focused on lifestyle changes (EASL et al., 2016; Chalasani et al., 2018).

Studies have shown that NAFLD is mainly characterized by hepatocyte inflammation and steatosis in the early stage and fibrosis and/or cirrhosis in the late stage (Wang et al., 2020). However, the pathogenesis of NAFLD has not been fully understood. In 1998, scientists first proposed the "two-hit" hypothesis to explain that steatosis (the first "hit") and other factors associated with free radicals (the second "hit") are necessary for NASH progression (Day and James, 1998). In recent years, based on animal models and descriptive clinical trials, the "multiple hits" hypothesis is widely accepted (Tilg and Moschen, 2010; Buzzetti et al., 2016; Tilg et al., 2021). The primary hit is the infiltration and pro-inflammatory state of macrophages in the visceral adipose 


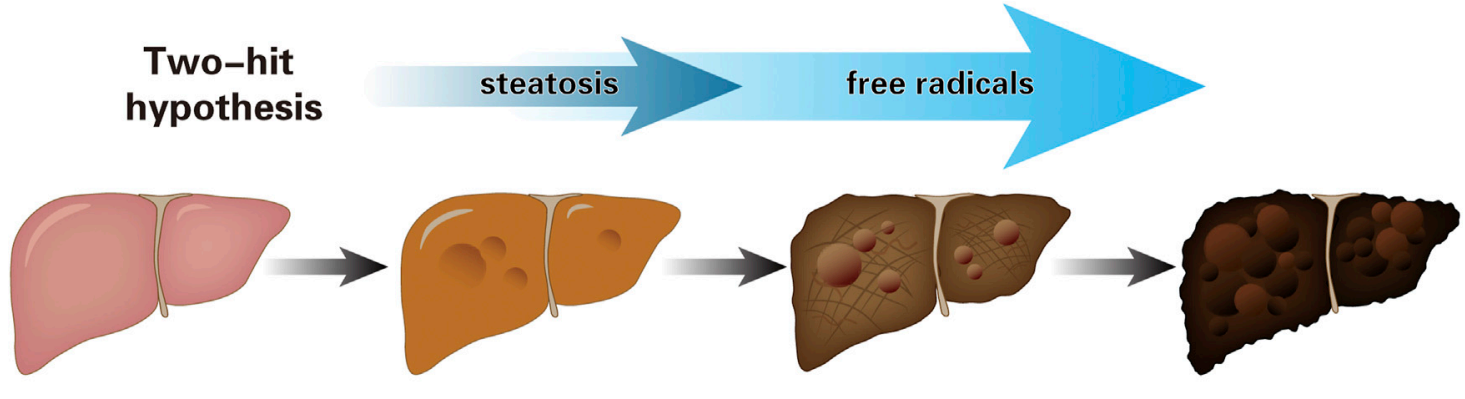

Healthy Liver

NAFL

NASH

Liver cirrhosis/HCC

\section{Multiple hits hypothesis}

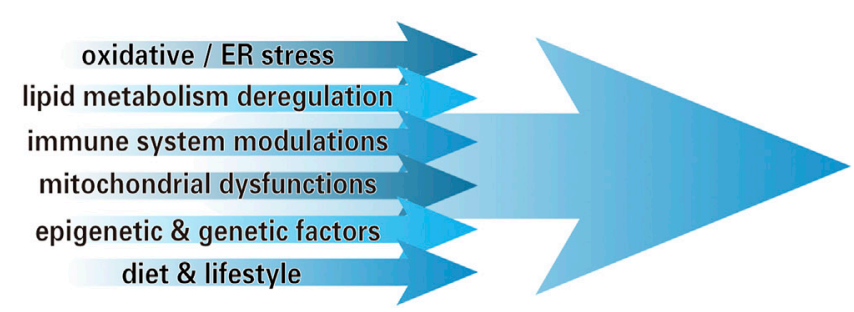

FIGURE 1 | The pathogenesis of NAFLD. Schematic representation illustrating cognition toward the progression of NAFLD: from "two-hit" hypothesis to "multiple hits" hypothesis. The early "two-hit" hypothesis, in which the first "hit" is steatosis, leads to the second "hit": oxidative stress, endotoxin, etc. The "multiple hits" hypothesis considers several parallel hits jointly affect the NAFLD pathogenesis, which includes, but is not limited to oxidative and/or ER stress, lipid metabolism deregulation, immune system modulations, mitochondrial dysfunctions, lifestyle, and epigenetic and genetic factors (NAFL, non-alcoholic fatty liver, i.e., simple steatosis without hepatocellular injury; NASH, non-alcoholic steatohepatitis; HCC, hepatocellular carcinoma; ER, endoplasmic reticulum).

tissue, resulting in IR. Meanwhile, the abnormal lipolysis increases the delivery of fatty acids to the liver, and along with steatosis, aggravates the lipid metabolic burden. The imbalance results in the formation of lipotoxic lipids that generate a series of multiple hits, including oxidative and/or endoplasmic reticulum (ER) stress, inflammasome activation, and apoptotic damage, followed by inflammation, tissue regeneration, and fibrogenesis (Tilg and Moschen, 2010; Bessone et al., 2019; Sanyal, 2019). Besides, mitochondrial dysfunctions, lifestyle, and epigenetic and genetic factors also jointly affect the occurrence and progression of the NAFLD (Loomba et al., 2021) (Figure 1).

Notch signaling pathway plays a crucial role in cell differentiation (Amsen et al., 2009; Amsen et al., 2015), proliferation (Bartolome et al., 2019), and apoptosis (Guruharsha et al., 2012). Recently, it has also been demonstrated that Notch is involved in liver development, homeostasis, and metabolism (Bi and Kuang, 2015; Geisler and Strazzabosco, 2015; Adams and Jafar-Nejad, 2019). However, the association of the Notch signaling with NAFLD has rarely been reported. Here we review the recent advances in Notch signaling in liver pathophysiology and analyze the Notch signaling pathway as a potential target to prevent and treat NAFLD.

\section{OVERVIEW OF NOTCH SIGNALING PATHWAY}

Notch signaling is a juxtracrine signal transduction mechanism that enables cell-cell communication directly (ArtavanisTsakonas et al., 1999). In mammals, four receptors (Notch1-4) and five ligands [Jagged (JAG) 1-2, Delta-like ligand (DLL) 1, 3, and 4] have been identified in canonical Notch signaling (D'Souza et al., 2010). In the liver of adults, four Notch receptors are expressed, while only two Notch ligands (JAG1 and DLL4) are expressed (Y. Chen et al., 2012). The ligand-receptor interaction is the initiation of Notch signaling pathway, making various cellular regulations more precise and orderly (Bray, 2016).

The core signaling pathway most commonly used to describe Notch-dependent processes is named the canonical Notch signaling pathway (Andersson et al., 2011; Guruharsha et al., 2012). The ligand presented by the Notch signal sending cell binds to the receptor on the signal-receiving cell. The endocytosis of the ligand leads to a conformational change of the Notch receptor, exposing the cleavage site of the ADAM10. Subsequent cleavage of the $\gamma$-secretase complex releases the Notch intracellular domain (NICD) (Kopan and Ilagan, 2009). NICD then migrates to the nucleus, binds to the transcription factor RBP-JK (also called CSL) (Kovall and Blacklow, 2010), and recruits the co-activator Mastermind-like (MAML) to initiate downstream gene transcription, including the hairy enhancer of split (HES) and HES-related (HEY) family genes (Nam et al., 2006; Wilson and Kovall, 2006; Bolos et al., 2007; Guruharsha et al., 2012) (Figure 2).

Different from other classical signal transduction processes, the canonical Notch signaling pathway is characterized by the lack of cascade amplification in the transduction process, and only NICD is generated after a Notch receptor is consumed. Therefore, its signal intensity is crucial for generating the corresponding cellular response, and any deviation in the expression level of any molecular component in the Notch 


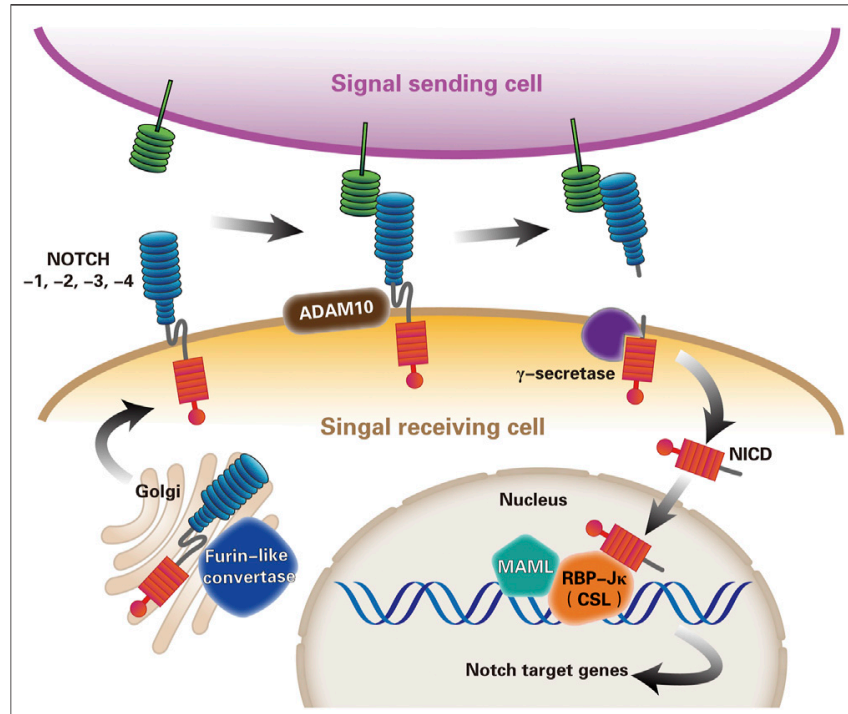

FIGURE 2 | The canonical Notch signaling pathway. Notch signaling pathway is currently thought to be activated by three steps of proteolysis. First, the mammalian Notch receptors are cleaved by a furin-like convertase in the Golgi compartment. After digestion, the extracellular subunits and transmembrane subunits formed by $\mathrm{Ca}^{2+}$ dependent non-covalent bonding to form heterodimers, and exocytosed to the cell membrane become mature Notch receptors. Second, Notch ligand-receptor binding enables proteolytic cleavage of the Notch extracellular domain by ADAM10 metalloprotease, and Notch receptor releases extracellular subunits. Third, $\gamma$-secretase complex cleaves the remnant receptor to allow the release and nuclear translocation of the NICD, where NICD forms a trimeric complex with transcription factor RBP$J_{\kappa}($ or CSL) and the co-activator MAML, imitating the expression of Notch target genes transcription. (ADAM, a disintegrin and metalloprotease10; RBP$\mathrm{J} \kappa$, recombination signal binding protein immunoglobulin kappa J; NICD, Notch intracellular domain; CSL, CBF1-suppressor of hairless-LAG1; MAML, mastermind-like). signaling pathway may have a vital impact (Andersson et al., 2011). For example, Alagille syndrome (AGS) is caused by mutations in the gene for the Notch ligand JAG1 and NOTCH2 receptor (McDaniell et al., 2006). Currently, various Notch signaling pathway modulation approaches have been explored, including inhibition of the ligand-receptor interaction and interference with the proteolytic process of the receptor (Groth and Fortini, 2012; Shao et al., 2012; Andersson and Lendahl, 2014). Several Notch inhibitors are demonstrated effects in the NAFLD (Table 1).

\section{NOTCH IN LIPID METABOLISM}

As the central hub of lipid homeostasis, the liver is responsible for coordinating the whole process of lipid circulation, including the synthesis, export, redistribution, and utilization of free fatty acids (Nguyen et al., 2008). The main pathways that constitute hepatic lipid homeostasis, including uptake of circulating lipids, de novo lipogenesis (DNL), fatty acid oxidation (FAO), and export as very-low-density lipoprotein (VLDL) particles (Gluchowski et al., 2017; Ipsen et al., 2018). Hallmarked by hepatic steatosis, NAFLD is connected with lipid metabolism. When lipid acquisition exceeds lipid disposal in the liver, that is, the uptake of fatty acids and DNL covering oxidation and output of fatty acids, hepatic steatosis occurred (Ipsen et al., 2018). Feng et al. (2017) proposed that no significant differences between free fatty acids (FFAs) in lean or obese patients with NAFLD were observed, and the value of serum FFAs in early diagnosis of NAFLD.

The studies suggested that nutrition-induced activation of mammalian target of rapamycin (mTOR) may cause an increase in liver lipid content, which also increases the activity of basal serine/threonine kinases, leading to a self-perpetuating

TABLE 1 | Major Notch signaling inhibitors in NAFLD

Inhibitor
Peroxiredoxin 6 (PRDX6)

Notch1 decoy

$\mathrm{N}$-[N-(3,5-Difluorophenacetyl)-L-alanyl]-Sphenylglycine t-butyl ester (DAPT)

Delta-like1 homolog (DLK1)

Triptolide (TP)

Hepatocyte Toll-like receptor 4 (TLR4)

Nuclear factor (erythroid-derived 2)-like 2 (Nrf2)

$\gamma$-secretase inhibitor (GSI)

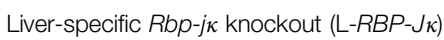
Silybin (SIL)

Delta-tocotrienol $(\delta-T)$

\section{Target}

Notch1

Notch1

Notch1

Notch1

Notch1

Jag1/JAG1

NICD

$\gamma$-secretase

$R B P-J \kappa$

NOTCH1

NOTCH1

\section{Function}

Improve lipid accumulation through induction of mitophagy

Decrease hepatic glucose production

Alleviate lipid accumulation and hepatocyte injury

Reduce hepatic steatosis and improve glucose and insulin tolerance

Initiate oxidative stress in hepatocyte

Reduce NASH related liver fibrosis

Ameliorate hepatic lipogenesis dyslipidemia and insulin resistance

Improve glucose metabolism and ameliorate liver fibrosis

Protect from obesity-induced insulin resistance Hepatoprotective and antitumorigenic effect in HCC cells

Reduce biochemical markers of hepatocellular injury and steatosis

\begin{tabular}{ll}
\multicolumn{1}{c}{ Object } & \multicolumn{1}{c}{ References } \\
Mice & Lee et al. (2019) \\
Mice & $\begin{array}{l}\text { Funahashi et al. (2008) Pajvani } \\
\text { et al. (2013) } \\
\text { Zhang et al. (2021) }\end{array}$ \\
Mice & Lee et al. (2016) \\
Mice & Shen et al. (2019) \\
Mice & Yu et al. (2021) \\
Mice/ & Human \\
Mice & Chartoumpekis et al. (2018)
\end{tabular}

Mice Richter et al. (2020)

Mice Pajvani et al. (2011)

Human Zhang et al. (2013)

Human Pervez et al. (2020) 
lipogenic cycle (Lamming and Sabatini, 2013; Caron et al., 2015; Han and Wang, 2018). Pajvani et al. (Pajvani et al., 2013) demonstrated that inhibition of Notch signaling prevented hepatic steatosis by blocking mTOR complex 1 (mTORC1) activity, which could be reversed by rapamycin treatment. They also showed that Notch signaling augmented mTORC1 function and SREBP1c-mediated lipogenesis and that inhibition of hepatic Notch signaling protects from the fatty liver by reducing DNL.

Although the specific pathogenesis of lipid metabolism disorder in NAFLD patients is still not completely clear, studies have shown it may be associated with Notch pathway regulation ( $\mathrm{Li}$ et al., 2019). Ding et al. (2020) investigated the dynamic role of Notch gene expression in the development of NAFLD in vitro and in vivo. They used palmitic acid (PA) and methionine-choline-deficient (MCD) models to assess notch signaling genes expression changes at different time points. Based on the characteristics of Notch mRNA expression levels, they evaluated that expression of Notch 3 mRNA has been dynamically changed significantly in the development of hepatic steatosis during NAFLD (Ding et al., 2020). Furthermore, Auguet et al. (2020) explored the association between the Notch transcriptional repressor and hepatic expression of lipid metabolism-related genes in a cohort of women with NAFLD. They found a negative relationship between hepatic HEY2 expression and low-density lipoprotein (LDL) cholesterol (Auguet et al., 2020).

\section{NOTCH IN INSULIN RESISTANCE}

It is generally recognized that IR is pivotal in the pathogenesis and progression of NAFLD (Lomonaco et al., 2012). IR is essentially a decrease in the sensitivity of whole-body, liver, and adipose tissue to insulin, which is involved in the development of hepatic steatosis (E. Bugianesi, 2010). In NAFLD patients, increases in circulating glucose and insulin associated with IR promote hepatic DNL (Smith et al., 2020). Specifically, when IR occurs, it causes an impaired ability of insulin to inhibit adipose tissue lipolysis, resulting in increased delivery of FFAs to the liver (Bugianesi et al., 2005). Meanwhile, large lipid deposition promotes IR, which leads to fasting hyperglycemia and compensatory hyperinsulinemia, further contributing to the pathophysiology of NAFLD via exacerbating DNL (Donnelly et al., 2005).

The abnormal activation of Notch signaling pathway and IR are closely linked. It is recognized factor forkhead box protein O1 (FOXO1) has a beneficial effect on insulin-mediated glucose homeostasis (Matsumoto et al., 2007; O-Sullivan et al., 2015). Notch signal mainly affects hepatic glucose via the synergistic effect of NICD and FoxO1 transcription. Glucose-6-phosphatase catalytic subunit (G6PC) and phosphoenolpyruvate carboxykinase (PCK1) are both rate-limiting enzymes of hepatic glycogenolysis and gluconeogenesis, which would be correlated with Notch activation (Valenti et al., 2013; Dongiovanni et al., 2016). Pajvani et al. (2011) reported that combined haploinsufficiency of FoxO1 and Notch1 notably improves insulin sensitivity in diet-induced IR. Hepatic overexpression of Notch1 regulates hepatic gluconeogenesis by inducing G6PC in a FoxO1-dependent mode, in turn, aggravates insulin resistance (Pajvani et al., 2011; Bernsmeier et al., 2016). Additionally, the reduction of metabolic activity in brown adipose tissue (BAT) has been found connected with IR in human (Stanford et al., 2013; Mottillo et al., 2016). Bi et al. (2014) revealed mice in which Notch1 or $R b p-j \kappa$ selectively deleted in adipocytes show upregulated expression of BAT-specific genes and improvement in glucose tolerance and insulin sensitivity.

Based on the close relation between IR and Notch, several possible pharmacological targets of NAFLD are identified. Blocking the abnormal expression of Notch at the gene level can inhibit the accumulation of liver gluconeogenesis and triglycerides (TGs), thereby reducing the risk of NAFLD. The cleavage of NICD by $\gamma$-secretase inhibitor (GSI) exhibited an improvement of glucose homeostasis and insulin sensitivity in diet-induced obese (DIO) mice (Pajvani et al., 2011). Lee et al. (2016) demonstrated that Delta-like 1 homolog (DLK1), an inhibitory regulator of Notch signaling, would reduce hepatic steatosis and hyperglycemia via exogenous administration. Chartoumpekis et al. (2018) showed nuclear factor (erythroidderived 2)-like 2 ( $\mathrm{Nrf2}$ ) could profoundly ameliorate hepatic lipogenesis and IR by repressing NICD. Besides, researchers also found plant extracts (such as curcumin) have been shown to suppress NOTCH1, which could ameliorate fatty liver and enhance insulin sensitivity in the high-fat diet (HFD) model (Zhao et al., 2017; Saadati et al., 2019; El et al., 2021).

\section{NOTCH IN OXIDATIVE STRESS}

Oxidative stress (OS) is a concept used to describe an imbalance between pro-oxidants and antioxidants, leading to cellular damage and tissue injury (Sies, 2015). The chronic highcalorie diet causes lipid accumulation in hepatocytes and excessive generation of reactive oxygen species (ROS) (Sahini and Borlak, 2014). Meanwhile, affected by lipotoxicity from high levels of lipid metabolites, OS inhibits insulin sensitivity and facilitates DNL (Gehrke and Schattenberg, 2020).

In the pathophysiological process of NAFLD, OS is considered a pivotal mediator of the inflammatory response (Koek et al., 2011). Notch signaling has been reported to be associated with steatosis and OS. It has been proposed that ROS like $\mathrm{H}_{2} \mathrm{O}_{2}$ regulates the expression of Notch (Marinho et al., 2014). Notch1 regulates the expression of lipid oxidation genes and exhibited an obvious lipid accumulation reduction in Notch1 deficient antisense transgenic (NAS) mice (Song et al., 2016). Similarly, Notch1 inhibitor reduces ethanol-induced OS and lipid accumulation in HepG2 cells (Wang et al., 2014).

Among the multiple mechanisms that accelerate the progression of NAFLD to NASH, mitochondrial dysfunction is the prime one (Caldwell et al., 1999). Mitochondrial abnormalities disrupt the balance between pro-oxidants and antioxidants, leading to an increase of FFAs (Begriche et al., 2013). Peroxiredoxin 6 (PRDX6) is a mitochondrial antioxidant enzyme and is highly expressed in the liver (Fisher, 2011; Arriga 
et al., 2019). Lee et al. (2019) demonstrated that PRDX6 induces effects of maintaining mitochondrial integrity and inhibits OSinduced Notch signaling, thereby reducing ROS production and lipid accumulation. They pointed out that PRDX6 mitophagymediated mechanisms offer endogenous protection against NAFLD (Lee et al., 2019).

Moreover, triptolide (TP) is the main ingredient of the medicinal herb Tripterygium wilfordii Hook f (TWHF) (Ziaei and Halaby, 2016). TP caused hepatotoxicity through initiating OS. Shen et al. (2019) investigated TP inhibited the protein expression of Notch1 and NICD, and the activation of Notch signaling has the potential to protect against TP-induced live injury. Interestingly, Huang et al. (2021) demonstrated that doserelated TP as an allosteric AMPK agonist alleviates NAFLD. Combined, the regulation of Notch signaling pathway may better enable TP to play a protective role in NAFLD.

\section{NOTCH IN INFLAMMATION AND FIBROGENESIS}

Liver fibrosis is a decisive factor of liver disease progression, particularly as it is associated with adverse prognosis and mortality in patients with NASH (Vilar-Gomez et al., 2018; Powell et al., 2021). Even in the early stage of fibrosis, it is shown a series of adverse liver-related events are gradually increasing (Angulo et al., 2015; Dulai et al., 2017; Hagstrom et al., 2017). In advanced NASH, hepatocytes are partially replaced by fibrotic scar tissue, the severe pathological change makes it difficult to treat NASH by correcting the underlying metabolic abnormality. Therefore, anti-fibrosis has become the focus of NASH therapy.

Notch activity is almost absent in healthy adult hepatocytes, mildly elevated in simple steatosis, and significantly increased in NASH (Valenti et al., 2013; Zhu et al., 2018). In various mouse models of fibrosis, over $80 \%$ of collagenous myofibroblasts are caused by hepatic stellate cell (HSC) (Mederacke et al., 2013). Notch-activated hepatocytes facilitate liver profibrogenic in NASH by both osteopontin (Opn) secretion mediated HSC activation in vitro and in vivo (Zhu et al., 2018), leading to a continuous extracellular matrix (ECM) accumulation and liver parenchyma gradually replaced by fibrous tissue (Mederacke et al., 2013). Conversely, in Notch loss-of-function mouse models, hepatocyte-specific liver inflammation and fibrosis are reduced, suggesting maladaptive hepatocytic Notch response to NASH-associated liver fibrosis (Zhu et al., 2018).

Sawitza et al. (2009) explored Jag1 as one of the cell surface ligands in Notch signaling activates HSC to stimulate $a$-SMA and collagen production. Yu et al. (2021) proved increasing Jag1 is responsible for fibrosis-inducing Notch reactivation. Also, other hepatic non-parenchymal cells could activate the Notch pathway to promote NASH latently through various mechanisms. Duan et al. (2018) investigated Notch activation in liver sinusoids endothelial cell (LSEC), which leads to HSC activation and the subsequent hepatic fibrosis, by downregulating eNOS-sGC signaling. Besides, researchers found that inhibitors inactivate M1 polarization of macrophage by regulating Notch signaling could reduce the secretion of inflammatory cytokine and fibrogenesis in $\mathrm{CCl}_{4}$-induced liver injury mice (Bansal et al., 2015; Xu et al., 2015; Sheng et al., 2020). Additionally, $\gamma$-secretase inhibitor (Chen et al., 2012) and Notch3 siRNA (Y. X. Chen et al., 2012) suppressed the myofibroblastic gene expression of rat HSC line by blocking Notch signaling. Therefore, selective interruption of these Notch-related targets may provide more anti-fibrosis strategies for NAFLD (Romeo, 2019).

\section{NOTCH IN AUTOPHAGY}

Autophagy is a process in which cells degrade and metabolize their own damaged organelles or protein aggregation (Wang et al., 2019), which plays a vital role in regulating multiple liver functions and maintaining hepatic homeostasis (Ueno and Komatsu, 2017). Accumulating evidence suggests autophagy regulates livermediated systemic glucose and lipid metabolism (Singh et al., 2009; Galluzzi et al., 2014). Meanwhile, the liver is surrounded by exogenous substances from the portal vein circulation, including potential inflammatory mediators, in which autophagy has major cell-protective and anti-inflammatory effects (Deretic et al., 2013; Deretic and Levine, 2018; Hazari et al., 2020). All of the above suggests autophagy is associated with the occurrence and development of various liver diseases such as NAFLD.

The lipid droplets (LDs) are specialized cytosolic organelles in which some organs including the liver store neutral lipids (such as TGs) to protect from lipotoxicity (Gross and Silver, 2014). The progression of LDs degradation is regarded as a specific form of autophagy, also known as lipophagy (Garcia et al., 2018). Recent studies have revealed that disturbances in lipophagy have been linked to hepatic lipid accumulation, the process of lipophagy could be regarded as a new way of controlling NAFLD development (Grefhorst et al., 2021).

Because autophagy can remove damaged organelles, autophagy may alleviate hepatocellular injury during NASH. The protective effects of carbamazepine-induced autophagy could reduce steatosis and improve IR in the NAFLD model (Lin et al., 2013). Indeed, modulating autophagy may prevent the progression of NAFLD. Zhang et al. (2021) investigated that Notch1 is an activated intensity of autophagy in FFA-treated HepG2 cells, and decreased Notch1 levels may alleviate hepatocyte damage by enhancing autophagy, which could be reversed by autophagy inhibitor chloroquine. Niture et al. (2018) demonstrated that inhibition of Notch reduced the expression of autophagy biomarker and serotonin-mediated liver cell steatosis. These findings provide helpful clues for the strategy of Notch signaling pathway to regulate autophagy and thereby remit the progression of NAFLD.

\section{NOTCH IN NAFLD-RELATED HCC}

HCC is the fourth leading cause of cancer-related deaths worldwide and occurs in patients with various chronic liver diseases (Bray et al., 2018; Llovet et al., 2021). Although hepatitis B virus (HBV) infection 


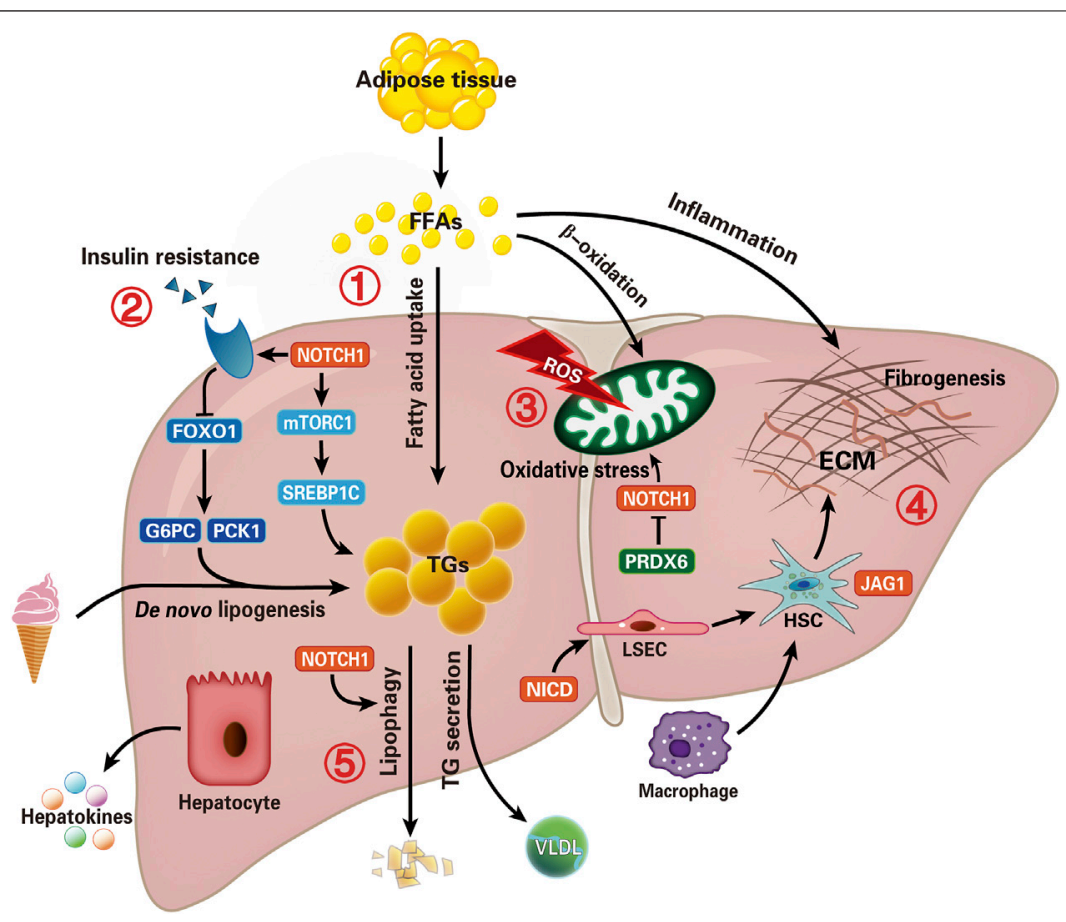

FIGURE 3 | Overview of potential therapeutic targets of Notch signal pathway in NAFLD. Summarize the recent critical advances evolving Notch signaling in the NAFLD. Intrahepatic lipid levels depend on the balance between lipid acquisition and disposal. Therefore, lipid accumulation is the result of uptake of fatty acids and de novo lipogenesis exceeding export as VLDL and oxidation of fatty acid, which is also a main pathophysiological change of NAFLD. The five potential pathways to intervene in NAFLD are focused on (1) hepatic lipid accumulation, (2) insulin resistance, (3) oxidative stress, (4) inflammation and fibrogenesis, and (5) autophagy (lipophagy) progression. Although several aspects of these functions remain to be fully understood, these findings offer an intriguing rationale for investigating Notchbased therapies in patients with NAFLD. Furthermore, the "hepatokines" secreted by hepatocytes may help reveal the complex molecular regulation in NAFLD. (NICD, Notch intracellular domain; FFAs, free fatty acids; mTORC1, mammalian target of rapamycin complex one; FOXO1, factor forkhead box protein O1; G6PC, glucose-6phosphatase catalytic subunit; PCK1, phosphoenolpyruvate carboxy kinase; TGs, triglycerides; VLDL, very-low-density lipoprotein; ROS, reactive oxygen species; PRDX6, peroxiredoxin 6; ECM, extracellular matrix; HSC, hepatic stellate cell; LSEC, liver sinusoids endothelial cell).

has been the prominent risk factor of HCC, NAFLD has become the most rapidly growing driver of HCC in many countries (Younossi et al., 2019; Hester et al., 2020). The incidence in patients with NAFLD-related HCC increases with the histological stage, which is highest in patients with NAFLD-cirrhosis (Ioannou, 2021).

Thus far, the exact pathogenesis underlying NAFLD-induced HCC is only incompletely understood but mainly focuses on the effects of DNA damage response, inflammation, autophagy, and intestinal microbiota (Anstee et al., 2019; Behary et al., 2021). In addition, the chronic activation of metabolic pathways seems to play a critical role (Baffy et al., 2012). These pathways may provoke infinite hepatocyte proliferation and genomic instability, and on the other hand, provide a microenvironment conducive to malignant transformation and tumor growth.

Recent studies suggest that Notch signaling pathway is frequently associated with tumorigenesis (Nowell and Radtke, 2017). Selective blocking of Notch1 inhibits cancer cell growth and deregulates angiogenesis (Wu et al., 2010). By performing RNA sequencing of hepatocyte populations HFD-fed reporter mice, Zhu et al. (2021) illustrated that Notch-active hepatocytes showed transcriptional enrichment of ECM-related genes, which may represent a mechanism that persists in the tumorigenic process. Furthermore, they found HFD-diet mice with Notchactive mutation spontaneously formed fully developed liver tumors (Zhu et al., 2021). Therefore, it can be inferred that the continuous activation of Notch signaling pathway promotes the occurrence of NAFLD-related HCC.

\section{CONCLUSION AND PERSPECTIVE}

NAFLD is a manifestation of metabolic syndrome in the liver. With the changes in lifestyle and dietary habits, the incidence of NAFLD is rising rapidly. The previous studies have revealed the significance of the Notch signaling pathway in metabolism. The abnormal expression of Notch may lead to several metabolic disorders, thus inducing NAFLD. Although the relation between NAFLD and Notch signaling has been observed both in vitro and in vivo, most of the research findings are based on phenotypic studies and the underlying mechanisms and potential associations between different Notch molecules, and require further in-depth research.

The development of liver-specific Notch inhibitors is pivotal for the treatment of NAFLD-related hepatic lipid accumulation, IR, OS, fibrogenesis, and autophagy progression (Figure 3). But 
until now, most intervention studies are conducted in animal models (especially mice), the potential role of Notch regulators in human NAFLD needs to be explored extensively. Recently, the rising field of "hepatokines" biology would help reveal the complex molecular regulation in NAFLD (Watt et al., 2019). If so, it would promote the development of more non-invasive diagnostic tests to improve early diagnosis rates.

There is no specific and effective pharmacotherapy toward NAFLD, however, some drugs have shown therapeutic potential by regulating a Notch signal pathway. Vitamin E (a-tocopherol) is a dietary antioxidant recommended as a treatment for NASH (Yakaryilmaz et al., 2007; Chalasani et al., 2018). Recent clinical research supports vitamin $\mathrm{E}$ use brought obvious histological benefits and improved prognosis in patients with NASH (Sato et al., 2015; Brunt et al., 2019; Vilar-Gomez et al., 2020). $\delta$-tocotrienol, an isomer of vitamin $\mathrm{E}$, has been explored to inhibit tumor invasion and metastasis via downregulating the NOTCH1 signaling pathway (Rajasinghe et al., 2018). Notably, Pervez et al. (2020) launched a randomized, double-blind, placebo-controlled trial of 71 patients with NAFLD. Compared with placebo, $\delta$-tocotrienol significantly reduced biochemical markers of hepatocellular injury and steatosis in patients (Pervez et al., 2020). Silybin (SIL), a hepatoprotective drug, could be an inhibitor targeting the NICD, RBP-J $\kappa$, and Hes1 proteins in HCC cells and exert antitumorigenic effects (Zhang et al., 2013).

The precise drug delivery without toxicity brings a wide application prospect for the treatment of NAFLD. A nanoparticle-mediated delivery system to target GSI in the liver (GSI NPs) has been developed (Richter et al., 2020),

\section{REFERENCES}

Adams, J. M., and Jafar-Nejad, H. (2019). The Roles of Notch Signaling in Liver Development and Disease. Biomolecules (Basel, Switzerland) 9 (10), 608. doi:10.3390/biom 9100608

Amsen, D., Antov, A., and Flavell, R. A. (2009). The Different Faces of Notch in T-Helper-Cell Differentiation. Nat. Rev. Immunol. 9 (2), 116-124. doi:10.1038/ nri2488

Amsen, D., Helbig, C., and Backer, R. A. (2015). Notch in T Cell Differentiation: All Things Considered. Trends Immunol. 36 (12), 802-814. doi:10.1016/ j.it.2015.10.007

Andersson, E. R., and Lendahl, U. (2014). Therapeutic Modulation of Notch Signalling - Are We There yet? Nat. Rev. Drug Discov. 13 (5), 357-378. doi: $10.1038 / \mathrm{nrd} 4252$

Andersson, E. R., Sandberg, R., and Lendahl, U. (2011). Notch Signaling: Simplicity in Design, Versatility in Function. Development 138 (17), 3593-3612. doi: $10.1242 / \mathrm{dev} .063610$

Angulo, P., Kleiner, D. E., Dam-Larsen, S., Adams, L. A., Bjornsson, E. S., Charatcharoenwitthaya, P., et al. (2015). Liver Fibrosis, but No Other Histologic Features, Is Associated with Long-Term Outcomes of Patients with Nonalcoholic Fatty Liver Disease. Gastroenterology 149 (2), 389-397. doi:10.1053/j.gastro.2015.04.043

Anstee, Q. M., Reeves, H. L., Kotsiliti, E., Govaere, O., and Heikenwalder, M. (2019). From NASH to HCC: Current Concepts and Future Challenges. Nat. Rev. Gastroenterol. Hepatol. 16 (7), 411-428. doi:10.1038/s41575019-0145-7

Arriga, R., Pacifici, F., Capuani, B., Coppola, A., Orlandi, A., Scioli, M. G., et al. (2019). Peroxiredoxin 6 Is a Key Antioxidant Enzyme in Modulating the Link which avoids goblet cell metaplasia caused by intestinal Notch inhibition (van Es et al., 2005). Based on similar studies above would advance clinical therapy research, thereby optimizing therapies for various NAFLD subtypes to increase the cure rate while complications can be decreased. In a word, findings on Notch signaling pathway research could bring NAFLD patients a hopeful future with ever more promising targets for prevention and treatment.

\section{AUTHOR CONTRIBUTIONS}

HX designed the outline of the review and drafted the manuscript. LW contributed his scientific advice and revision of the manuscript. All authors read and approved the submitted version.

\section{FUNDING}

This study was supported by the MOST 2016YFA0102100 (The National Key Research and Development Program of China: Stem Cell and Translational Research), and NSFC 81670863, 81422009, 81401940, 81770560, 81800533.

\section{ACKNOWLEDGMENTS}

We thank Dr. Hua Han and Dr. Kefeng Dou from the Fourth Military Medical University, for their constructive scientific advice.

between Glycemic and Lipogenic Metabolism. Oxid Med. Cel Longev 2019, 9685607. doi:10.1155/2019/9685607

Artavanis-Tsakonas, S., Rand, M. D., and Lake, R. J. (1999). Notch Signaling: Cell Fate Control and Signal Integration in Development. Science 284 (5415), 770-776. doi:10.1126/science.284.5415.770

Auguet, T., Bertran, L., Binetti, J., Aguilar, C., Martínez, S., Guiu Jurado, E., et al. (2020). Hepatocyte Notch Signaling Deregulation Related to Lipid Metabolism in Women with Obesity and Nonalcoholic Fatty Liver. Obesity 28 (8), 1487-1493. doi:10.1002/oby.22873

Baffy, G., Brunt, E. M., and Caldwell, S. H. (2012). Hepatocellular Carcinoma in Non-alcoholic Fatty Liver Disease: an Emerging Menace. J. Hepatol. 56 (6), 1384-1391. doi:10.1016/j.jhep.2011.10.027

Bansal, R., van Baarlen, J., Storm, G., and Prakash, J. (2015). The Interplay of the Notch Signaling in Hepatic Stellate Cells and Macrophages Determines the Fate of Liver Fibrogenesis. Sci. Rep. 5, 18272. doi:10.1038/srep18272

Bartolome, A., Zhu, C., Sussel, L., and Pajvani, U. B. (2019). Notch Signaling Dynamically Regulates Adult Beta Cell Proliferation and Maturity. J. Clin. Invest. 129 (1), 268-280. doi:10.1172/JCI98098

Begriche, K., Massart, J., Robin, M. A., Bonnet, F., and Fromenty, B. (2013). Mitochondrial Adaptations and Dysfunctions in Nonalcoholic Fatty Liver Disease. Hepatology 58 (4), 1497-1507. doi:10.1002/hep.26226

Behary, J., Amorim, N., Jiang, X. T., Raposo, A., Gong, L., McGovern, E., et al. (2021). Gut Microbiota Impact on the Peripheral Immune Response in Nonalcoholic Fatty Liver Disease Related Hepatocellular Carcinoma. Nat. Commun. 12 (1), 187. doi:10.1038/s41467-020-20422-7

Bernsmeier, C., Dill, M. T., Provenzano, A., Makowska, Z., Krol, I., Muscogiuri, G., et al. (2016). Hepatic Notch1 Deletion Predisposes to Diabetes and Steatosis via Glucose-6-Phosphatase and Perilipin-5 Upregulation. Lab. Invest. 96 (9), 972-980. doi:10.1038/labinvest.2016.75 
Bessone, F., Razori, M. V., and Roma, M. G. (2019). Molecular Pathways of Nonalcoholic Fatty Liver Disease Development and Progression. Cell Mol. Life Sci. 76 (1), 99-128. doi:10.1007/s00018-018-2947-0

Bi, P., and Kuang, S. (2015). Notch Signaling as a Novel Regulator of Metabolism. Trends Endocrinology Metabolism 26 (5), 248-255. doi:10.1016/ j.tem.2015.02.006

Bi, P., Shan, T., Liu, W., Yue, F., Yang, X., Liang, X., et al. (2014). Inhibition of Notch Signaling Promotes browning of white Adipose Tissue and Ameliorates Obesity. Nat. Med. 20 (8), 911-918. doi:10.1038/nm.3615

Bolos, V., Grego-Bessa, J., and de la Pompa, J. L. (2007). Notch Signaling in Development and Cancer.

Bray, F., Ferlay, J., Soerjomataram, I., Siegel, R. L., Torre, L. A., and Jemal, A. (2018). Global Cancer Statistics 2018: GLOBOCAN Estimates of Incidence and Mortality Worldwide for 36 Cancers in 185 Countries. CA Cancer J. Clin. 68 (6), 394-424. doi:10.3322/caac.21492

Bray, S. J. (2016). Notch Signalling in Context. Nat. Rev. Mol. Cel Biol. 17 (11), 722-735. doi:10.1038/nrm.2016.94

Brunt, E. M., Kleiner, D. E., Wilson, L. A., Sanyal, A. J., and Neuschwander-Tetri, B. A. (2019). Improvements in Histologic Features and Diagnosis Associated with Improvement in Fibrosis in Nonalcoholic Steatohepatitis: Results from the Nonalcoholic Steatohepatitis Clinical Research Network Treatment Trials. Hepatology 70 (2), 522-531. doi:10.1002/hep.30418

Bugianesi, E., Gastaldelli, A., Vanni, E., Gambino, R., Cassader, M., Baldi, S., et al. (2005). Insulin Resistance in Non-diabetic Patients with Non-alcoholic Fatty Liver Disease: Sites and Mechanisms. Diabetologia 48 (4), 634-642. doi:10.1007/s00125-005-1682-x

Bugianesi, E. (2010). Insulin Resistance in Nonalcoholic Fatty Liver Disease. Curr. Pharm. Des. 16 (17).

Buzzetti, E., Pinzani, M., and Tsochatzis, E. A. (2016). The Multiple-Hit Pathogenesis of Non-alcoholic Fatty Liver Disease (NAFLD). Metabolism 65 (8), 1038-1048. doi:10.1016/j.metabol.2015.12.012

Caldwell, S. H., Swerdlow, R. H., Khan, E. M., Iezzoni, J. C., Hespenheide, E. E., Parks, J. K., et al. (1999). Mitochondrial Abnormalities in Non-alcoholic Steatohepatitis. J. Hepatol. 31 (3), 430-434. doi:10.1016/s0168-8278(99) 80033-6

Caron, A., Richard, D., and Laplante, M. (2015). The Roles of mTOR Complexes in Lipid Metabolism. Annu. Rev. Nutr. 35, 321-348. doi:10.1146/annurev-nutr071714-034355

Chalasani, N., Younossi, Z., Lavine, J. E., Charlton, M., Cusi, K., Rinella, M., et al. (2018). The Diagnosis and Management of Nonalcoholic Fatty Liver Disease: Practice Guidance from the American Association for the Study of Liver Diseases. Hepatology 67 (1), 328-357. doi:10.1002/hep.29367

Chartoumpekis, D. V., Yagishita, Y., Fazzari, M., Palliyaguru, D. L., Rao, U. N. M., Zaravinos, A., et al. (2018). Nrf2 Prevents Notch-Induced Insulin Resistance and Tumorigenesis in Mice. JCI Insight 3 (5), 97735. doi:10.1172/ jci.insight. 97735

Chen, Y. X., Weng, Z. H., and Zhang, S. L. (2012). Notch3 Regulates the Activation of Hepatic Stellate Cells. World J. Gastroenterol. 18 (12), 1397-1403. doi:10.3748/wjg.v18.i12.1397

Chen, Y., Zheng, S., Qi, D., Zheng, S., Guo, J., Zhang, S., et al. (2012). Inhibition of Notch Signaling by a Gamma-Secretase Inhibitor Attenuates Hepatic Fibrosis in Rats. PLoS One 7 (10), e46512. doi:10.1371/ journal.pone.0046512

D’Souza, B., Meloty-Kapella, L., and Weinmaster, G. (2010). Canonical and Noncanonical Notch Ligands. Curr. Top. Dev. Biol. 92, 73-129. doi:10.1016/S00702153(10)92003-6

Day, C. P., and James, O. F. W. (19981943). Steatohepatitis: A Tale of Two "Hits". Gastroenterol. (N.Y, N.Y. 114 (4), 842-845. doi:10.1016/S0016-5085(98) 70599-2

Deretic, V., and Levine, B. (2018). Autophagy Balances Inflammation in Innate Immunity. Autophagy 14 (2), 243-251. doi:10.1080/ 15548627.2017.1402992

Deretic, V., Saitoh, T., and Akira, S. (2013). Autophagy in Infection, Inflammation and Immunity. Nat. Rev. Immunol. 13 (10), 722-737. doi:10.1038/nri3532

Ding, W., Wu, W., Chen, Y., Chen, H., Fan, J., and Qiao, L. (2020). Expression of Notch Family Is Altered in Non-alcoholic Fatty Liver Disease. Mol. Med. Rep. 22 (3), 1702-1708. doi:10.3892/mmr.2020.11249
Dongiovanni, P., Rametta, R., Meroni, M., and Valenti, L. (2016). The Role of Insulin Resistance in Nonalcoholic Steatohepatitis and Liver Disease Development-Aa Potential Therapeutic Target? Expert Rev. Gastroenterol. Hepatol. 10 (2), 229-242. doi:10.1586/ 17474124.2016.1110018

Donnelly, K. L., Smith, C. I., Schwarzenberg, S. J., Jessurun, J., Boldt, M. D., and Parks, E. J. (2005). Sources of Fatty Acids Stored in Liver and Secreted via Lipoproteins in Patients with Nonalcoholic Fatty Liver Disease. J. Clin. Invest. 115 (5), 1343-1351. doi:10.1172/JCI23621

Duan, J. L., Ruan, B., Yan, X. C., Liang, L., Song, P., Yang, Z. Y., et al. (2018). Endothelial Notch Activation Reshapes the Angiocrine of Sinusoidal Endothelia to Aggravate Liver Fibrosis and blunt Regeneration in Mice. Hepatology 68 (2), 677-690. doi:10.1002/hep.29834

Dulai, P. S., Singh, S., Patel, J., Soni, M., Prokop, L. J., Younossi, Z., et al. (2017). Increased Risk of Mortality by Fibrosis Stage in Nonalcoholic Fatty Liver Disease: Systematic Review and Meta-Analysis. Hepatology 65 (5), 1557-1565. doi:10.1002/hep. 29085

Easl, E. A. F. T., Easd, E. A. F. T., and Easo, E. A. F. T. (2016). EASL-EASDEASO Clinical Practice Guidelines for the Management of Non-alcoholic Fatty Liver Disease. J. Hepatol. 64 (6), 1388-1402. doi:10.1016/ j.jhep.2015.11.004

El, S. G., El-Shafey, E. S., and Elsherbiny, E. S. (2021). Ziziphus Spina-Christi (L.) Fortified with Camellia Sinensis Mediates Apoptosis, Notch-1 Signaling, and Mitigates Obesity-Induced Non-alcoholic Fatty Liver. J. Food Biochem., e13849. doi:10.1111/jfbc.13849

Feng, R., Luo, C., Li, C., Du, S., Okekunle, A. P., Li, Y., et al. (2017). Free Fatty Acids Profile Among Lean, Overweight and Obese Non-alcoholic Fatty Liver Disease Patients: a Case - Control Study. Lipids Health Dis. 16 (1), 165. doi:10.1186/ s12944-017-0551-1

Fisher, A. B. (2011). Peroxiredoxin 6: a Bifunctional Enzyme with Glutathione Peroxidase and Phospholipase A(2) Activities. Antioxid. Redox Signal. 15 (3), 831-844. doi:10.1089/ars.2010.3412

Francque, S., and Vonghia, L. (2019). Pharmacological Treatment for Nonalcoholic Fatty Liver Disease. Adv. Ther. 36 (5), 1052-1074. doi:10.1007/ s12325-019-00898-6

Funahashi, Y., Hernandez, S. L., Das, I., Ahn, A., Huang, J., Vorontchikhina, M., et al. (2008). A Notch1 Ectodomain Construct Inhibits Endothelial Notch Signaling, Tumor Growth, and Angiogenesis. Cancer Res. 68 (12), 4727-4735. doi:10.1158/0008-5472.CAN-07-6499

Galluzzi, L., Pietrocola, F., Levine, B., and Kroemer, G. (2014). Metabolic Control of Autophagy. Cell 159 (6), 1263-1276. doi:10.1016/ j.cell.2014.11.006

Garcia, E. J., Vevea, J. D., and Pon, L. A. (2018). Lipid Droplet Autophagy during Energy Mobilization, Lipid Homeostasis and Protein Quality Control. Front. Biosci. (Landmark Ed. 23, 1552-1563. doi:10.2741/4660

Gehrke, N., and Schattenberg, J. M. (2020). Metabolic Inflammation-A Role for Hepatic Inflammatory Pathways as Drivers of Comorbidities in Nonalcoholic Fatty Liver Disease? Gastroenterology 158 (7), 1929-1947. doi:10.1053/ j.gastro.2020.02.020

Geisler, F., and Strazzabosco, M. (2015). Emerging Roles of Notch Signaling in Liver Disease. Hepatology 61 (1), 382-392. doi:10.1002/hep.27268

Gluchowski, N. L., Becuwe, M., Walther, T. C., and Farese, R. V. (2017). Lipid Droplets and Liver Disease: from Basic Biology to Clinical Implications. Nat. Rev. Gastroenterol. Hepatol. 14 (6), 343-355. doi:10.1038/ nrgastro.2017.32

Grefhorst, A., van de Peppel, I. P., Larsen, L. E., Jonker, J. W., and Holleboom, A. G. (2021). The Role of Lipophagy in the Development and Treatment of Nonalcoholic Fatty Liver Disease. Front. Endocrinol. 11. doi:10.3389/ fendo.2020.601627

Gross, D. A., and Silver, D. L. (2014). Cytosolic Lipid Droplets: from Mechanisms of Fat Storage to Disease. Crit. Rev. Biochem. Mol. Biol. 49 (4), 304-326. doi:10.3109/10409238.2014.931337

Groth, C., and Fortini, M. E. (2012). Therapeutic Approaches to Modulating Notch Signaling: Current Challenges and Future Prospects. Semin. Cel Dev Biol 23 (4), 465-472. doi:10.1016/j.semcdb.2012.01.016

Guruharsha, K. G., Kankel, M. W., and Artavanis-Tsakonas, S. (2012). The Notch Signalling System: Recent Insights into the Complexity of a Conserved Pathway. Nat. Rev. Genet. 13 (9), 654-666. doi:10.1038/nrg3272 
Hagstrom, H., Nasr, P., Ekstedt, M., Hammar, U., Stal, P., Hultcrantz, R., et al. (2017). Fibrosis Stage but Not NASH Predicts Mortality and Time to Development of Severe Liver Disease in Biopsy-Proven NAFLD. J. Hepatol. 67 (6), 1265-1273. doi:10.1016/j.jhep.2017.07.027

Han, J., and Wang, Y. (2018). mTORC1 Signaling in Hepatic Lipid Metabolism. Protein Cell 9 (2), 145-151. doi:10.1007/s13238-017-0409-3

Hazari, Y., Bravo-San, P. J., Hetz, C., Galluzzi, L., and Kroemer, G. (2020). Autophagy in Hepatic Adaptation to Stress. J. Hepatol. 72 (1), 183-196. doi:10.1016/j.jhep.2019.08.026

Hester, D., Golabi, P., Paik, J., Younossi, I., Mishra, A., and Younossi, Z. M. (2020). Among Medicare Patients with Hepatocellular Carcinoma, Nonalcoholic Fatty Liver Disease Is the Most Common Etiology and Cause of Mortality. J. Clin. Gastroenterol. 54 (5), 459-467. doi:10.1097/ MCG.0000000000001172

Huang, D. Q., El-Serag, H. B., and Loomba, R. (2021). Global Epidemiology of NAFLD-Related HCC: Trends, Predictions, Risk Factors and Prevention. Nat. Rev. Gastroenterol. Hepatol. 18 (4), 223-238. doi:10.1038/s41575020-00381-6

Huang, R., Guo, F., Li, Y., Liang, Y., Li, G., Fu, P., et al. (2021). Activation of AMPK by Triptolide Alleviates Nonalcoholic Fatty Liver Disease by Improving Hepatic Lipid Metabolism, Inflammation and Fibrosis. Phytomedicine 92, 153739. doi:10.1016/j.phymed.2021.153739

Ioannou, G. N. (2021). Epidemiology and Risk-Stratification of NAFLDAssociated HCC. J. Hepatol. 8278. 02007. doi:10.1016/j.jhep.2021.08.012

Ipsen, D. H., Lykkesfeldt, J., and Tveden-Nyborg, P. (2018). Molecular Mechanisms of Hepatic Lipid Accumulation in Non-alcoholic Fatty Liver Disease. Cell Mol. Life Sci. 75 (18), 3313-3327. doi:10.1007/s00018-018-2860-6

Jarvis, H., Craig, D., Barker, R., Spiers, G., Stow, D., Anstee, Q. M., et al. (2020). Metabolic Risk Factors and Incident Advanced Liver Disease in Non-alcoholic Fatty Liver Disease (NAFLD): A Systematic Review and Meta-Analysis of Population-Based Observational Studies. PLOS Med. 17 (4), e1003100. doi:10.1371/journal.pmed.1003100

Koek, G. H., Liedorp, P. R., and Bast, A. (2011). The Role of Oxidative Stress in Non-alcoholic Steatohepatitis. Clin. Chim. Acta 412 (15-16), 1297-1305. doi:10.1016/j.cca.2011.04.013

Kopan, R., and Ilagan, M. X. (2009). The Canonical Notch Signaling Pathway: Unfolding the Activation Mechanism. Cell 137 (2), 216-233. doi:10.1016/ j.cell.2009.03.045

Kovall, R. A., and Blacklow, S. C. (2010). Mechanistic Insights into Notch Receptor Signaling from Structural and Biochemical Studies. Curr. Top. Dev. Biol. 92, 31-71. doi:10.1016/S0070-2153(10)92002-4

Lamming, D. W., and Sabatini, D. M. (2013). A Central Role for mTOR in Lipid Homeostasis. Cel Metab. 18 (4), 465-469. doi:10.1016/ j.cmet.2013.08.002

Lee, D. H., Jung, Y. Y., Park, M. H., Jo, M. R., Han, S. B., Yoon, D. Y., et al. (2019). Peroxiredoxin 6 Confers Protection against Nonalcoholic Fatty Liver Disease through Maintaining Mitochondrial Function. Antioxid. Redox Signaling 31 (5), 387-402. doi:10.1089/ars.2018.7544

Lee, Y. H., Yun, M. R., Kim, H. M., Jeon, B. H., Park, B. C., Lee, B. W., et al. (2016). Exogenous Administration of DLK1 Ameliorates Hepatic Steatosis and Regulates Gluconeogenesis via Activation of AMPK. Int. J. Obes. (Lond) 40 (2), 356-365. doi:10.1038/ijo.2015.173

Li, T., Yan, H., Geng, Y., Shi, H., Li, H., Wang, S., et al. (2019). Target Genes Associated with Lipid and Glucose Metabolism in Non-alcoholic Fatty Liver Disease. Lipids Health Dis. 18 (1), 211. doi:10.1186/s12944-0191154-9

Lin, C. W., Zhang, H., Li, M., Xiong, X., Chen, X., Chen, X., et al. (2013). Pharmacological Promotion of Autophagy Alleviates Steatosis and Injury in Alcoholic and Non-alcoholic Fatty Liver Conditions in Mice. J. Hepatol. 58 (5), 993-999. doi:10.1016/j.jhep.2013.01.011

Llovet, J. M., Kelley, R. K., Villanueva, A., Singal, A. G., Pikarsky, E., Roayaie, S., et al. (2021). Hepatocellular Carcinoma. Nat. Rev. Dis. Primers 7 (1), 6. doi:10.1038/s41572-020-00240-3

Lomonaco, R., Ortiz-Lopez, C., Orsak, B., Webb, A., Hardies, J., Darland, C., et al. (2012). Effect of Adipose Tissue Insulin Resistance on Metabolic Parameters and Liver Histology in Obese Patients with Nonalcoholic Fatty Liver Disease. Hepatology 55 (5), 1389-1397. doi:10.1002/hep.25539
Loomba, R., Friedman, S. L., and Shulman, G. I. (2021). Mechanisms and Disease Consequences of Nonalcoholic Fatty Liver Disease. Cell 184 (10), 2537-2564. doi:10.1016/j.cell.2021.04.015

Marinho, H. S., Real, C., Cyrne, L., Soares, H., and Antunes, F. (2014). Hydrogen Peroxide Sensing, Signaling and Regulation of Transcription Factors. Redox Biol. 2, 535-562. doi:10.1016/j.redox.2014.02.006

Matsumoto, M., Pocai, A., Rossetti, L., Depinho, R. A., and Accili, D. (2007). Impaired Regulation of Hepatic Glucose Production in Mice Lacking the Forkhead Transcription Factor Foxol in Liver. Cell Metab 6 (3), 208-216. doi:10.1016/j.cmet.2007.08.006

McDaniell, R., Warthen, D. M., Sanchez-Lara, P. A., Pai, A., Krantz, I. D., Piccoli, D. A., et al. (2006). NOTCH2 Mutations Cause Alagille Syndrome, a Heterogeneous Disorder of the Notch Signaling Pathway. Am. J. Hum. Genet. 79 (1), 169-173. doi:10.1086/505332

Mederacke, I., Hsu, C. C., Troeger, J. S., Huebener, P., Mu, X., Dapito, D. H., et al. (2013). Fate Tracing Reveals Hepatic Stellate Cells as Dominant Contributors to Liver Fibrosis Independent of its Aetiology. Nat. Commun. 4, 2823. doi:10.1038/ ncomms 3823

Mottillo, E. P., Desjardins, E. M., Crane, J. D., Smith, B. K., Green, A. E., Ducommun, S., et al. (2016). Lack of Adipocyte AMPK Exacerbates Insulin Resistance and Hepatic Steatosis through Brown and Beige Adipose Tissue Function. Cel Metab. 24 (1), 118-129. doi:10.1016/j.cmet.2016.06.006

Nam, Y., Sliz, P., Song, L., Aster, J. C., and Blacklow, S. C. (2006). Structural Basis for Cooperativity in Recruitment of MAML Coactivators to Notch Transcription Complexes. Cell 124 (5), 973-983. doi:10.1016/ j.cell.2005.12.037

Nguyen, P., Leray, V., Diez, M., Serisier, S., Bloc, H. J. L., Siliart, B., et al. (2008). Liver Lipid Metabolism. J. Anim. Physiol. Anim. Nutr. 92 (3), 272-283. doi:10.1111/j.1439-0396.2007.00752.x

Niture, S., Gyamfi, M. A., Kedir, H., Arthur, E., Ressom, H., Deep, G., et al. (2018). Serotonin Induced Hepatic Steatosis Is Associated with Modulation of Autophagy and Notch Signaling Pathway. Cell Commun. Signaling 16 (1), 6. doi:10.1186/s12964-018-0282-6

Nowell, C. S., and Radtke, F. (2017). Notch as a Tumour Suppressor. Nat. Rev. Cancer 17 (3), 145-159. doi:10.1038/nrc.2016.145

O-Sullivan, I., Zhang, W., Wasserman, D. H., Liew, C. W., Liu, J., Paik, J., et al. (2015). FoxO1 Integrates Direct and Indirect Effects of Insulin on Hepatic Glucose Production and Glucose Utilization. Nat. Commun. 6, 7079. doi:10.1038/ncomms8079

Pajvani, U. B., Qiang, L., Kangsamaksin, T., Kitajewski, J., Ginsberg, H. N., and Accili, D. (2013). Inhibition of Notch Uncouples Akt Activation from Hepatic Lipid Accumulation by Decreasing mTorcl Stability. Nat. Med. 19 (8), 1054-1060. doi:10.1038/nm.3259

Pajvani, U. B., Shawber, C. J., Samuel, V. T., Birkenfeld, A. L., Shulman, G. I., Kitajewski, J., et al. (2011). Inhibition of Notch Signaling Ameliorates Insulin Resistance in a FoxO1-dependent Manner. Nat. Med. 17 (8), 961-967. doi: $10.1038 / \mathrm{nm} .2378$

Pervez, M. A., Khan, D. A., Slehria, A. U. R., and Ijaz, A. (2020). Delta-tocotrienol Supplementation Improves Biochemical Markers of Hepatocellular Injury and Steatosis in Patients with Nonalcoholic Fatty Liver Disease: A Randomized, Placebo-Controlled Trial. Complement. Therapies Med. 52, 102494. doi:10.1016/j.ctim.2020.102494

Powell, E. E., Wong, V. W., and Rinella, M. (2021). Non-alcoholic Fatty Liver Disease. The Lancet. doi:10.1016/S0140-6736(20)32511-3

Rajasinghe, L. D., Pindiprolu, R. H., and Gupta, S. V. (2018). Delta-tocotrienol Inhibits Non-small-cell Lung Cancer Cell Invasion via the Inhibition of NFkappaB, uPA Activator, and MMP-9. Onco Targets Ther. 11, 4301-4314. doi:10.2147/OTT.S160163

Richter, L. R., Wan, Q., Wen, D., Zhang, Y., Yu, J., Kang, J. K., et al. (2020). Targeted Delivery of Notch Inhibitor Attenuates Obesity-Induced Glucose Intolerance and Liver Fibrosis. ACS Nano 14 (6), 6878-6886. doi:10.1021/ acsnano.0c01007

Romeo, S. (2019). Notch and Nonalcoholic Fatty Liver and Fibrosis. N. Engl. J. Med. 380 (7), 681-683. doi:10.1056/NEJMcibr1815636

Saadati, S., Hatami, B., Yari, Z., Shahrbaf, M. A., Eghtesad, S., Mansour, A., et al. (2019). The Effects of Curcumin Supplementation on Liver Enzymes, Lipid Profile, Glucose Homeostasis, and Hepatic Steatosis and Fibrosis in Patients 
with Non-alcoholic Fatty Liver Disease. Eur. J. Clin. Nutr. 73 (3), 441-449. doi:10.1038/s41430-018-0382-9

Sahini, N., and Borlak, J. (2014). Recent Insights into the Molecular Pathophysiology of Lipid Droplet Formation in Hepatocytes. Prog. Lipid Res. 54, 86-112. doi:10.1016/j.plipres.2014.02.002

Sanyal, A. J. (2019). Past, Present and Future Perspectives in Nonalcoholic Fatty Liver Disease. Nat. Rev. Gastroenterol. Hepatol. 16, 377-386.

Sato, K., Gosho, M., Yamamoto, T., Kobayashi, Y., Ishii, N., Ohashi, T., et al. (2015). Vitamin E Has a Beneficial Effect on Nonalcoholic Fatty Liver Disease: a Meta-Analysis of Randomized Controlled Trials. Nutrition 31 (7-8), 923-930. doi:10.1016/j.nut.2014.11.018

Sawitza, I., Kordes, C., Reister, S., and Haussinger, D. (2009). The Niche of Stellate Cells within Rat Liver. Hepatology 50 (5), 1617-1624. doi:10.1002/ hep. 23184

Shao, H., Huang, Q., and Liu, Z. J. (2012). Targeting Notch Signaling for Cancer Therapeutic Intervention. Adv. Pharmacol. 65, 191-234. doi:10.1016/B978-012-397927-8.00007-5

Shen, F., Xiong, Z., Kong, J., Wang, L., Cheng, Y., Jin, J., et al. (2019). Triptolide Impairs Thioredoxin System by Suppressing Notch1-Mediated PTEN/Akt/ Txnip Signaling in Hepatocytes. Toxicol. Lett. 300, 105-115. doi:10.1016/ j.toxlet.2018.10.024

Sheng, J., Zhang, B., Chen, Y., and Yu, F. (2020). Capsaicin Attenuates Liver Fibrosis by Targeting Notch Signaling to Inhibit TNF-Alpha Secretion from M1 Macrophages. Immunopharmacol Immunotoxicol 42 (6), 556-563. doi:10.1080/ 08923973.2020.1811308

Sies, H. (2015). Oxidative Stress: a Concept in Redox Biology and Medicine. Redox Biol. 4, 180-183. doi:10.1016/j.redox.2015.01.002

Singh, R., Kaushik, S., Wang, Y., Xiang, Y., Novak, I., Komatsu, M., et al. (2009). Autophagy Regulates Lipid Metabolism. Nature 458 (7242), 1131-1135. doi:10.1038/nature07976

Smith, G. I., Shankaran, M., Yoshino, M., Schweitzer, G. G., Chondronikola, M., Beals, J. W., et al. (2020). Insulin Resistance Drives Hepatic De Novo Lipogenesis in Nonalcoholic Fatty Liver Disease. J. Clin. Invest. 130 (3), 1453-1460. doi:10.1172/JCI134165

Song, N. J., Yun, U. J., Yang, S., Wu, C., Seo, C. R., Gwon, A. R., et al. (2016). Notch1 Deficiency Decreases Hepatic Lipid Accumulation by Induction of Fatty Acid Oxidation. Sci. Rep. 6, 19377. doi:10.1038/srep19377

Stanford, K. I., Middelbeek, R. J., Townsend, K. L., An, D., Nygaard, E. B., Hitchcox, K. M., et al. (2013). Brown Adipose Tissue Regulates Glucose Homeostasis and Insulin Sensitivity. J. Clin. Invest. 123 (1), 215-223. doi:10.1172/JCI62308

Tilg, H., Adolph, T. E., and Moschen, A. R. (2021). Multiple Parallel Hits Hypothesis in Nonalcoholic Fatty Liver Disease: Revisited after a Decade. Hepatol. (Baltimore, Md 73 (2), 833-842. doi:10.1002/hep.31518

Tilg, H., and Moschen, A. R. (2010). Evolution of Inflammation in Nonalcoholic Fatty Liver Disease: The Multiple Parallel Hits Hypothesis. Hepatol. (Baltimore, Md 52 (5), 1836-1846. doi:10.1002/hep.24001

Ueno, T., and Komatsu, M. (2017). Autophagy in the Liver: Functions in Health and Disease. Nat. Rev. Gastroenterol. Hepatol. 14 (3), 170-184. doi:10.1038/ nrgastro.2016.185

Valenti, L., Mendoza, R. M., Rametta, R., Maggioni, M., Kitajewski, C., Shawber, C. J., et al. (2013). Hepatic Notch Signaling Correlates with Insulin Resistance and Nonalcoholic Fatty Liver Disease. Diabetes 62 (12), 4052-4062. doi:10.2337/ db13-0769

van Es, J. H., van Gijn, M. E., Riccio, O., van den Born, M., Vooijs, M., Begthel, H., et al.(2005). Notch/gamma-secretase Inhibition Turns Proliferative Cells in Intestinal Crypts and Adenomas into Goblet Cells. Nature 435 (7044), 959-963. doi:10.1038/nature03659

Vernon, G., Baranova, A., and Younossi, Z. M. (2011). Systematic Review: the Epidemiology and Natural History of Non-alcoholic Fatty Liver Disease and Non-alcoholic Steatohepatitis in Adults. Aliment. Pharmacol. Ther. 34 (3), 274-285. doi:10.1111/j.1365-2036.2011.04724.x

Vilar-Gomez, E., Calzadilla-Bertot, L., Wai-Sun, W. V., Castellanos, M., Aller-de, L. F. R., Metwally, M., et al. (2018). Fibrosis Severity as a Determinant of Causespecific Mortality in Patients with Advanced Nonalcoholic Fatty Liver Disease: A Multi-National Cohort Study. Gastroenterology 155 (2), 443-457. doi:10.1053/.j.gastro.2018.04.034
Vilar-Gomez, E., Vuppalanchi, R., Gawrieh, S., Ghabril, M., Saxena, R., Cummings, O. W., et al. (2020). Vitamin E Improves Transplant-free Survival and Hepatic Decompensation Among Patients with Nonalcoholic Steatohepatitis and Advanced Fibrosis. Hepatology 71 (2), 495-509. doi:10.1002/hep.30368

Wang, C., Li, X., Wang, H., Xie, Q., and Xu, Y. (2014). Notch1-nuclear Factor kappaB Involves in Oxidative Stress-Induced Alcoholic Steatohepatitis. Alcohol Alcohol 49 (1), 10-16. doi:10.1093/alcalc/agt167

Wang, H., Liu, Y., Wang, D., Xu, Y., Dong, R., Yang, Y., et al. (2019). The Upstream Pathway of mTOR-Mediated Autophagy in Liver Diseases. Cells 8 (12), 1597. doi: $10.3390 /$ cells 8121597

Wang, Y., Wong, G. L., He, F., Sun, J., Chan, A. W., Yang, J., et al. (2020). Quantifying and Monitoring Fibrosis in Non-alcoholic Fatty Liver Disease Using Dual-Photon Microscopy. Gut 69 (6), 1116-1126. doi:10.1136/gutjnl2019-318841

Watt, M. J., Miotto, P. M., De Nardo, W., and Montgomery, M. K. (2019). The Liver as an Endocrine Organ-Linking NAFLD and Insulin Resistance. Endocr. Rev. 40 (5), 1367-1393. doi:10.1210/er.2019-00034

Wilson, J. J., and Kovall, R. A. (2006). Crystal Structure of the CSL-NotchMastermind Ternary Complex Bound to DNA. Cell 124 (5), 985-996. doi:10.1016/j.cell.2006.01.035

Wong, V. W., Wong, G. L., Choi, P. C., Chan, A. W., Li, M. K., Chan, H., et al. (2010). Disease Progression of Non-alcoholic Fatty Liver Disease: a Prospective Study with Paired Liver Biopsies at 3years. Gut 59 (7), 969-974. doi:10.1136/ gut.2009.205088

Wu, Y., Cain-Hom, C., Choy, L., Hagenbeek, T. J., de Leon, G. P., Chen, Y., et al. (2010). Therapeutic Antibody Targeting of Individual Notch Receptors. Nature 464 (7291), 1052-1057. doi:10.1038/nature08878

Xu, J., Chi, F., Guo, T., Punj, V., Lee, W. N., French, S. W., et al. (2015). NOTCH Reprograms Mitochondrial Metabolism for Proinflammatory Macrophage Activation. J. Clin. Invest. 125 (4), 1579-1590. doi:10.1172/JCI76468

Yakaryilmaz, F., Guliter, S., Savas, B., Erdem, O., Ersoy, R., Erden, E., et al. (2007). Effects of Vitamin E Treatment on Peroxisome Proliferator-Activated Receptor-Alpha Expression and Insulin Resistance in Patients with Nonalcoholic Steatohepatitis: Results of a Pilot Study. Intern. Med. J. 37 (4), 229-235. doi:10.1111/j.1445-5994.2006.01295.x

Younossi, Z., Anstee, Q. M., Marietti, M., Hardy, T., Henry, L., Eslam, M., et al. (2018). Global burden of NAFLD and NASH: Trends, Predictions, Risk Factors and Prevention. Nat. Rev. Gastroenterol. Hepatol. 15 (1), 11-20. doi:10.1038/ nrgastro.2017.109

Younossi, Z. M., Koenig, A. B., Abdelatif, D., Fazel, Y., Henry, L., and Wymer, M. (2016). Global Epidemiology of Nonalcoholic Fatty Liver Disease-MetaAnalytic Assessment of Prevalence, Incidence, and Outcomes. Hepatology 64 (1), 73-84. doi:10.1002/hep.28431

Younossi, Z. M. (2019). Non-alcoholic Fatty Liver Disease - A Global Public Health Perspective. J. Hepatol. 70 (3), 531-544. doi:10.1016/ j.jhep.2018.10.033

Younossi, Z., Stepanova, M., Ong, J. P., Jacobson, I. M., Bugianesi, E., Duseja, A., et al. (2019). Nonalcoholic Steatohepatitis Is the Fastest Growing Cause of Hepatocellular Carcinoma in Liver Transplant Candidates. Clin. Gastroenterol. Hepatol. 17 (4), 748-755. doi:10.1016/j.cgh.2018.05.057

Yu, J., Zhu, C., Wang, X., Kim, K., Bartolome, A., Dongiovanni, P., et al. (2021). Hepatocyte TLR4 Triggers Inter-hepatocyte Jagged1/Notch Signaling to Determine NASH-Induced Fibrosis. Sci. Transl Med. 13 (599), 1692. doi:10.1126/scitranslmed.abe1692

Zhang, M., Wu, P., Li, M., Guo, Y., Tian, T., Liao, X., et al. (2021). Inhibition of Notch1 Signaling Reduces Hepatocyte Injury in Nonalcoholic Fatty Liver Disease via Autophagy. Biochem. Biophysical Res. Commun. 547, 131-138. doi:10.1016/j.bbrc.2021.02.039

Zhang, S., Yang, Y., Liang, Z., Duan, W., Yang, J., Yan, J., et al. (2013). Silybinmediated Inhibition of Notch Signaling Exerts Antitumor Activity in Human Hepatocellular Carcinoma Cells. PLoS One 8 (12), e83699. doi:10.1371/ journal.pone.0083699

Zhao, N. J., Liao, M. J., Wu, J. J., and Chu, K. X. (2017). Curcumin Suppresses Notch-1 Signaling: Improvements in Fatty Liver and Insulin Resistance in Rats. Mol. Med. Rep. 17 (1), 819-826. doi:10.3892/mmr.2017.7980 
Zhu, C., Ho, Y., Salomao, M. A., Dapito, D. H., Bartolome, A., Schwabe, R. F., et al. (2021). Notch Activity Characterizes a Common Hepatocellular Carcinoma Subtype with Unique Molecular and Clinicopathologic Features. J. Hepatol. 74 (3), 613-626. doi:10.1016/j.jhep.2020.09.032

Zhu, C., Kim, K., Wang, X., Bartolome, A., Salomao, M., Dongiovanni, P., et al. (2018). Hepatocyte Notch Activation Induces Liver Fibrosis in Nonalcoholic Steatohepatitis. Sci. Transl Med. 10 (468), 344. doi:10.1126/scitranslmed.aat0344

Ziaei, S., and Halaby, R. (2016). Immunosuppressive, Anti-inflammatory and Anticancer Properties of Triptolide: A Mini Review. Avicenna J. Phytomed 6 (2), 149-164.

Conflict of Interest: The authors declare that the research was conducted in the absence of any potential conflict of interest.
Publisher's Note: All claims expressed in this article are solely those of the authors and do not necessarily represent those of their affiliated organizations, or those of the publisher, the editors, and the reviewers. Any product that may be evaluated in this article, or claim that may be made by its manufacturer, is not guaranteed or endorsed by the publisher.

Copyright (c) $2021 \mathrm{Xu}$ and Wang. This is an open-access article distributed under the terms of the Creative Commons Attribution License (CC BY). The use, distribution or reproduction in other forums is permitted, provided the original author $(s)$ and the copyright owner(s) are credited and that the original publication in this journal is cited, in accordance with accepted academic practice. No use, distribution or reproduction is permitted which does not comply with these terms. 


\section{GLOSSARY}

AGS Alagille syndrome

DIO diet-induced obese

DLK1 Delta-like 1 homolog

DNL de novo lipogenesis

ECM extracellular matrix

ER endoplasmic reticulum

FAO fatty acid oxidation

FFAs free fatty acids

FOXO1 factor forkhead box protein O1

G6PC glucose-6-phosphatase catalytic subunit

GSI $\gamma$-secretase inhibitor

HCC hepatocellular carcinoma

HFD high-fat diet

HSC hepatic stellate cell

IR insulin resistanceinsulin resistance

IR insulin resistanceinsulin resistance

LDs lipid droplets

LSEC liver sinusoids endothelial cell

MCD methionine-choline-deficient
mTOR mammalian target of rapamycin

mTORC1 mTOR complex 1

NAFL non-alcoholic fatty liver

NAFLD non-alcoholic fatty liver disease

NASH non-alcoholic fatty steatohepatitis

NAS Notch1 deficient antisense transgenic

NICD Notch intracellular domain

Nrf2 nuclear factor (erythroid-derived 2)-like 2

Opn osteopontin

OS oxidative stress

PA palmitic acid

PCK1 phosphoenolpyruvate carboxy kinase

PRDX6 Peroxiredoxin 6

ROS reactive oxygen species

SIL Silybin; $\delta$-T(Delta-tocotrienol)

SS simple steatosis

TGs triglycerides

TP triptolide

TWHF tripterygium wilfordii Hook $\mathrm{f}$

VLDL very-low-density lipoprotein 